\title{
GSTח stimulates caveolin-1-regulated polyamine uptake via actin remodeling
}

\author{
Takeshi Uemura $^{1}$, George Tsaprailis ${ }^{2}$ and Eugene W. Gerner ${ }^{3}$ \\ ${ }^{1}$ Amine Pharma Research Institute, Chuo-ku, Chiba 260-0856, Japan \\ ${ }^{2}$ Center for Toxicology, College of Pharmacy, Tucson, Arizona 85721, USA \\ ${ }^{3}$ Cancer Prevention Pharmaceuticals, Tucson, Arizona 85718, USA \\ Correspondence to: Takeshi Uemura, email: vemura@amine-pharma.com
}

Keywords: polyamine; caveolin; GSTT; transport; actin

Received: June 08, $2019 \quad$ Accepted: August 16, $2019 \quad$ Published: October 01, 2019

Copyright: Uemura et al. This is an open-access article distributed under the terms of the Creative Commons Attribution License 3.0 (CC BY 3.0), which permits unrestricted use, distribution, and reproduction in any medium, provided the original author and source are credited.

\section{ABSTRACT}

Polyamines spermidine and spermine, and their diamine precursor putrescine, are essential for normal cellular functions in both pro- and eukaryotes. Cellular polyamine levels are regulated by biosynthesis, degradation and transport. Transport of dietary and luminal bacterial polyamines in gastrointestinal (GI) tissues plays a significant role in tissue polyamine homeostasis. We have reported that caveolin-1 play an inhibitory role in polyamine uptake in GI tissues. We investigated the mechanism of caveolin-1-regulated polyamine transport. We found that glutathione $S$-transferase $\Pi$ (GSTח) was secreted from caveolin-1 knockdown cells and stimulated spermidine transport in human colon-derived HCT116 cells. GSTח secreted in the medium increased $S$-glutathionylated protein level in the plasma membrane fraction. Proteomic analysis revealed that actin was $S$-glutathionylated by GSTח. Immunofluorescence microscopy demonstrated that actin filaments around plasma membrane were $S$-glutathionylated in caveolin-1 knockdown cells. Inhibition of actin remodeling by jasplakinolide caused a decrease in polyamine uptake activity. These data support a model in which caveolin-1 negatively regulates polyamine uptake by inhibiting GSTח secretion, which stimulates actin remodeling and endocytosis.

\section{INTRODUCTION}

Polyamines, spermidine and spermine, and their precursor putrescine are essential factors for normal cellular functions [1]. Polyamines can bind to anions such as DNA, RNA and ATP, and regulate their functions [2]. Recent studies demonstrated that polyamines enhanced the synthesis of several proteins at the level of translation [3-5]. Polyamines are also required for posttranslational modification of eukaryotic translation initiation factor 5A (eIF5A), which is implicated in translation elongation and termination [6]. Although polyamines are required for normal cellular functions, high concentrations of polyamines are toxic to cells [7]. The cellular polyamine levels are tightly regulated by biosynthesis, degradation and transport. The transport plays important roles in polyamine homeostasis in addition to de novo synthesis and degradation systems [8]. The major sources of exogenous polyamines come from diet and luminal bacteria [9].

We have identified amino acid transporter SLC3A2 as a polyamine transporter in colon cancer derived cells [10]. SLC3A2 associates with polyamine catabolic enzyme spermidine/spermine $N^{1}$-acetyl transferase, SAT1, and catalyzes the export of acetylated polyamines by a polyamine/arginine exchange reaction. In certain conditions such as low intracellular polyamine levels, SLC3A2 catalyzes polyamine uptake [11]. We have also reported that caveolar endocytic mechanisms mediates polyamine uptake and caveolin-1 play an inhibitory role in polyamine uptake in gastrointestinal tissues and human colon-derived HCT116 cells [11, 12].

Caveolin-1 is a major structural protein of caveolae in nonmuscle cells and is implicated in endocytosis and signal transductions [13]. Caveolin-1 is also involved in protein trafficking and secretion $[14,15]$. Our previous 
study has demonstrated that knockdown of caveolin-1 expression using anti-sense RNA increased polyamine uptake in HCT116 cells [12]. It is suggested that polyamines are associated with lipid raft and internalized via caveolar endocytic pathway, but a detailed mechanism of caveolin-1-regulated polyamine uptake is not yet elucidated.

In this report, we investigated the mechanism of caveolin-1-regulated polyamine uptake. We found that glutathione $S$-transferase $\pi$ (GST $\pi$ ) was secreted from caveolin-1 deficient cells and stimulated polyamine uptake in human colon-derived cells.

\section{RESULTS}

\section{GST $\pi$ secreted from caveolin-1 knockdown cells stimulates polyamine uptake}

We have reported that knockdown of caveolin-1 caused an increase in polyamine uptake [12]. Caveolin-1 is involved in endocytosis and protein secretion [14, 15]. We hypothesized that protein (s) secreted by

\section{HCT116/Mock}
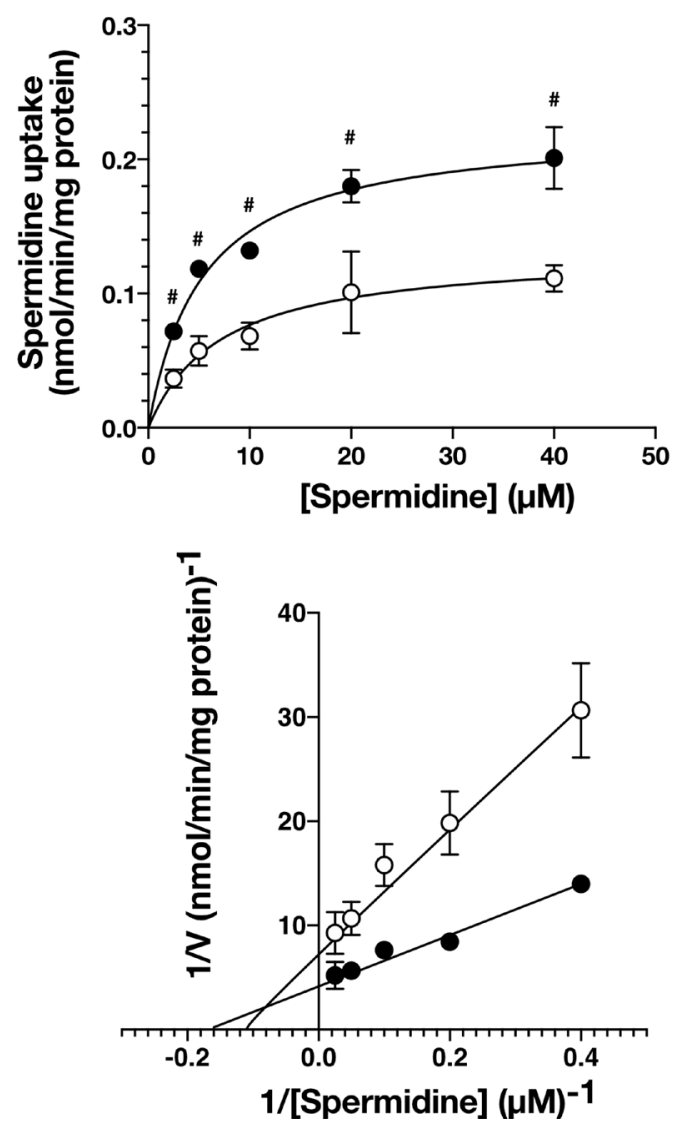

caveolin-1 dependent mechanism can affect polyamine transport. To test this idea, we examined the effect of culture medium on the polyamine uptake activity using human colorectal carcinoma cell line HCT116 stably transfected with the expression vector containing caveolin-1-encoding cDNA in the antisense orientation (HCT116/Cav-1 AS) and empty vector transfected cells (HCT116/Mock). HCT116/Mock and HCT116/Cav-1 AS cells were cultured in the medium from HCT116/ Mock (Control Supernatant, CS) and HCT116/Cav1 AS (Mutant Supernatant, MS) culture, respectively, and spermidine uptake activity was measured. As shown in Figure 1, spermidine uptake activity was significantly increased when HCT116/Mock cells were cultured in MS. The Vmax value was about twice as high in HCT116/Mock cells cultured in MS, whereas $K m$ values were not significantly affected (Table 1). Spermidine uptake activity was slightly increased in HCT116/Cav-1 AS cells when cultured in MS but the difference between CS was not significant (Table 1). The growth and viability were not significantly different in both cell lines (data not shown). These results suggested

\section{HCT116/Cav-1 AS}
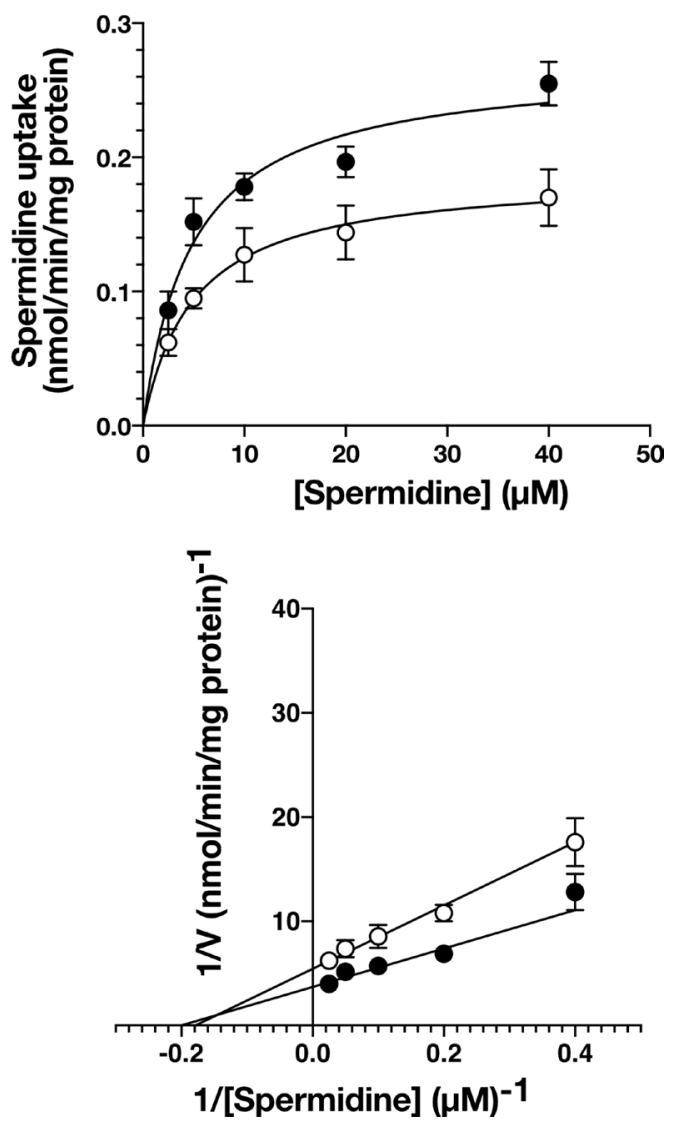

Figure 1: The effect of culture medium on spermidine uptake activity. HCT116/Mock and caveolin-1 knockdown cells HCT116/ Cav-1 AS were cultured in the control supernatant (CS, white circles) or mutant supernatant (MS, black circles) for 2 days. Spermidine uptake activity was measured by incubating cells with radiolabeled spermidine for $5 \mathrm{~min}$ as described in MATERIALS AND METHODS section. Values are mean $\pm \mathrm{SD}$ of triplicate determinations. ${ }^{*}, p<0.01$. against HCT116/Mock cultured in CS. The corresponding double reciprocal plots are shown in bottom panels. 
Table 1: Km and Vmax values for spermidine uptake

\begin{tabular}{lccc}
\hline Cells & Medium $^{\mathbf{a}}$ & $\boldsymbol{K}^{\mathbf{b}}$ & $\boldsymbol{V m a x}^{\mathbf{b}}$ \\
\hline & & $\mu \mathrm{M}$ & $\mathrm{nmol} / \mathbf{m i n} / \mathbf{m g}$ protein \\
HCT116/Mock & CS & $6.41 \pm 1.04$ & $0.12 \pm 0.01$ \\
& MS & $5.27 \pm 0.93^{\mathrm{ns}}$ & $0.22 \pm 0.04^{*}$ \\
HCT116/Cav-1 AS & CS & $5.22 \pm 0.27$ & $0.19 \pm 0.02^{*}$ \\
& MS & $4.81 \pm 0.69^{\mathrm{ns}}$ & $0.26 \pm 0.10^{\mathrm{ns}}$ \\
\hline
\end{tabular}

a, Cells were cultured in the medium from HCT116/Mock (Control Supernatant, CS) or HCT116/Cav-1 AS (Mutant Supernatant, MS) culture.

b, Values are mean \pm standard error of triplicate determinations.

*, $p<0.05$ against HCT116/Mock cells cultured in CS ns, not significant against HCT116/Mock or HCT116/Cav-1 AS cells cultured in CS.

that the culture medium of HCT116/Cav-1 AS cells (MS) contained protein (s) that stimulated spermidine uptake. We analyzed proteins secreted into the medium by SDSPAGE. HCT116/Mock and HCT116/Cav-1 AS cells were cultured in the serum-free Opti-MEM I. After 2 days culture, media were collected, filtered to remove cells, and proteins were resolved in a $12 \%$ polyacrylamide gel. As shown in Figure 2A, a $22 \mathrm{KDa}$ band was found in HCT116/Cav-1 AS culture medium. This band was subjected to peptide sequencing by liquid chromatography followed by tandem mass spectrometry. The $22 \mathrm{KDa}$ band was identified as glutathione $S$-transferase $\pi(\mathrm{GST} \pi)$ with 14 unique peptides comprising $60 \%$ sequence coverage (Supplementary Table 1). Western blot analysis of the medium using the anti-GST $\pi$ antibody confirmed the expression of GST $\pi$ in the medium of the HCT116/Cav-1 AS culture (Figure 2A). These results indicate that GST $\pi$ secreted from HCT116/Cav-1 AS cells can stimulate spermidine uptake. To confirm that GST $\pi$ stimulated polyamine uptake, we treated the culture medium with anti-GST $\pi$ antibody. As shown in Figure 2B, mutant supernatant (MS) stimulated spermine uptake. The treatment of MS with anti-GST $\pi$ antibody diminished this effect of the medium, whereas non-specific normal goat IgG did not. Addition of purified GST $\pi$ protein to the medium increased spermidine uptake. These results confirmed that GST $\pi$ in the medium stimulated spermidine uptake.

\section{A GST $\pi$ levels in medium}

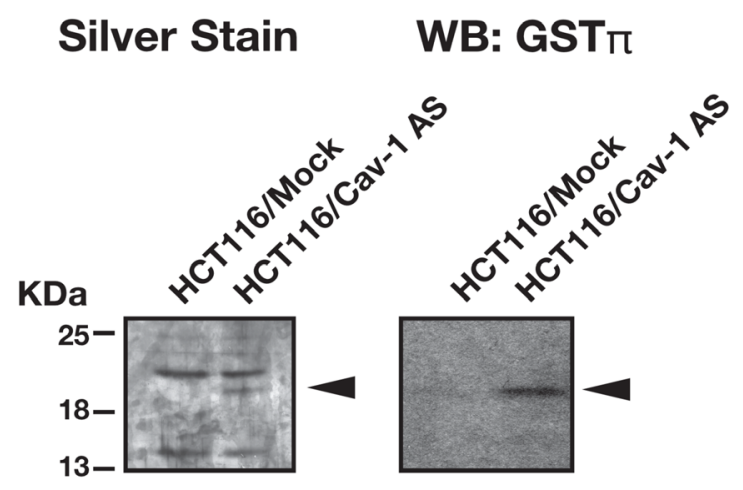

B Effect of anti-GST $\pi$ and GST $\pi$ protein

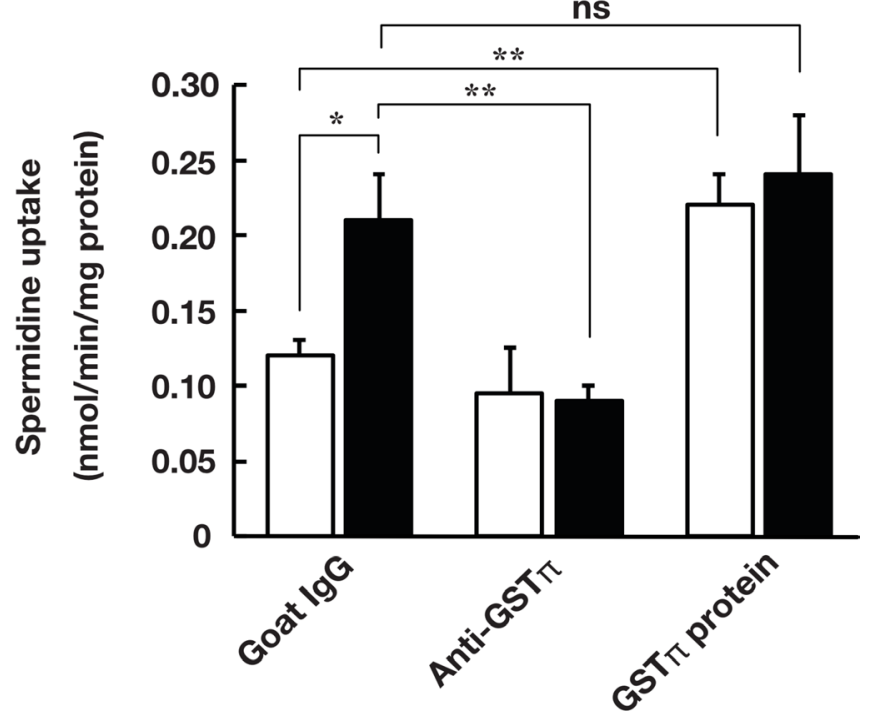

Figure 2: GST $\pi$ was highly expressed in the culture medium of HCT116/Cav-1 AS cells and stimulated spermidine uptake. (A) HCT116/Mock and HCT116/Cav-1 AS cells were cultured in the serum-free Opti-MEM I for 2 days. Proteins in the medium were separated in 12\% SDS-PAGE and stained as described in MATERIALS AND METHODS section. An arrowhead indicates the band highly expressed in the HCT116/Cav-1 AS culture medium. GST $\pi$ protein was detected by western blotting using an anti-GST $\pi$ antibody as described in MATERIALS AND METHODS section. (B) HCT116/Mock cells were cultured in control supernatant (white bar) or mutant supernatant (black bar) in the presence of $0.5 \mathrm{mg} / \mathrm{mL}$ anti-GST $\pi$ antibody, normal goat IgG or $10 \mathrm{ng} / \mathrm{mL}$ purified GST $\pi$ protein. Spermidine uptake activities were measured as described in MATERIALS AND METHODS section. Values are mean $\pm \mathrm{SD}$ of triplicate determinations. ${ }^{*}, p<0.05,{ }^{* *}, p<0.01$, ns, not significant. 


\section{Knockdown of caveolin-1 increases membrane associated GST $\pi$}

We examined the effect of caveolin-1 on GST $\pi$ expression. As shown in Figure 3A, plasma membrane associated GST $\pi$ was increased by mutant supernatant (MS) in HCT116/Mock cells. Plasma membrane associated GST $\pi$ level was also high in HCT116/Cav-1 AS cells whereas the levels of GST $\pi$ in whole cell extract were the same in all culture conditions. The separation of plasma membrane from whole cell extract was tested using flotilin 1 as a marker for caveolae containing plasma membrane and $\beta$-tubulin for a cytosolic fraction. Judged from the data, plasma membrane fraction was separated from whole cell extract. GST $\pi$ mRNA levels were not changed in all culture conditions (Figure 3B). These results suggested that caveolin-1 negatively regulated the secretion of GST $\pi$. GST $\pi$ catalyzes $S$-glutathionylation of cysteine residues in proteins under nitrosative stress conditions [16]. We next examined the effect of the culture medium on $S$-glutathionylated protein levels. HCT116/Mock and HCT116/Cav-1 AS cells were cultured in CS or MS and stained with anti-GST $\pi$ and anti-glutathione antibodies. As indicated by white arrowheads in Figure 4, MS upregulated $S$-gulutathionylated protein and GST $\pi$ levels on the cell surface. The shape of HCT116/Mock cells cultured in MS was slightly changed from rounded to elongated (Figure 4A and 4B). This may be caused by a $S$-glutathionylation of proteins. Experiments were repeated three times and the same results were obtained. This result indicated that secreted GST $\pi$ catalyzed $S$-glutathionylation of protein (s) on the cell surface.

\section{Actin $S$-glutathionylated by GST $\pi$ regulates polyamine uptake}

To identify $S$-glutathionylated protein, we performed immunoprecipitation using anti-glutathione antibody and

\section{A Protein levels}

$\beta$-Tubulin - - - - - -

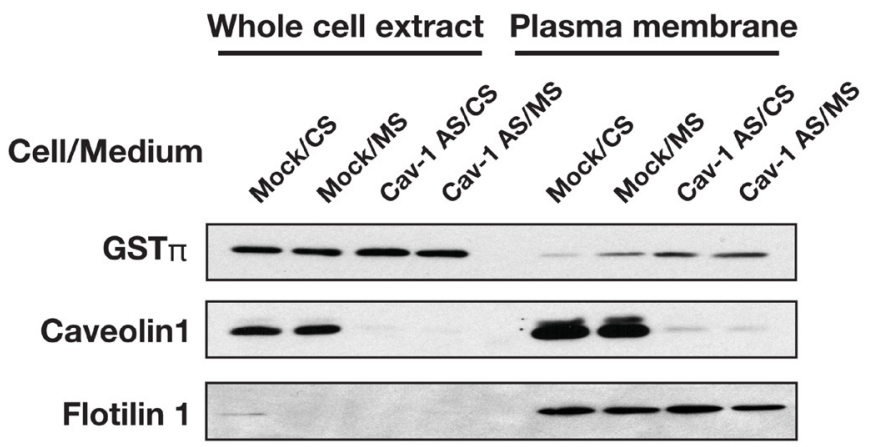

plasma membrane fractions prepared from HCT116/Mock and HCT116/Cav-1 AS cells. As shown in Figure 5A, antiglutathione antibody precipitated $42 \mathrm{KDa}$ protein which was identified as $\beta$-actin with 15 unique peptides comprising $47 \%$ sequence coverage (Supplementary Information) by proteomic analysis. Western blot analysis demonstrated that protein precipitated with anti-glutathione antibody was $\beta$-actin, and $\beta$-actin was $S$-glutathionylated (Figure $5 \mathrm{~B}$ and $5 \mathrm{C})$. Immunofluorescence microscopy revealed that signal from $S$-glutathionylated protein was colocalized with F-actin on the cell surface area in HCT116/Cav-1 AS cells (Figure 6, white arrowheads). On the other hand, G-actin stained with DNase I did not colocalize with $S$-glutathionylated proteins (Figure 6). The experiment was repeated three times and the same results were obtained. We next examined the role of actin $S$-glutathionylation on polyamine uptake. It has been reported that $S$-glutathionylation of actin regulated actin filament formation by inhibiting actin polymerization [16, 17]. It was also reported that actin depolymerization induced caveolae-mediated endocytosis [18]. We hypothesized that $S$-glutathionylation of actin induced actin depolymerization and caveolar endocytosis. To test this idea, we treated cells with jasplakinolide, an inhibitor of actin depolymerization [19]. As shown in Figure 7A, jasplakinolide treatment inhibited spermidine uptake. In this experimental condition, jasplakinolide did not induce significant cell death (Figure 7B). Jasplakinolide was washed away before spermidine uptake assay so it was not likely the drug affected the binding of spermidine to the polyamine receptor. These data indicated that $S$-glutathionylation of actin by GST $\pi$ induced actin depolymerization and endocytosis of polyamines.

\section{DISCUSSION}

In this report, we investigated the mechanism of caveolin-1-regulated polyamine uptake. We found that

\section{B mRNA levels}

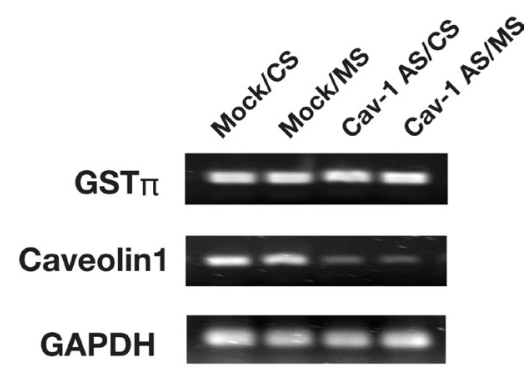

Figure 3: The effect of culture medium and caveolin-1 on the GST $\pi$ expression. (A) HCT116/Mock and HCT116/Cav-1 AS cells were cultured in control supernatant (CS) or mutant supernatant (MS) and plasma membrane fractions were prepared. GST $\pi$, caveolin-1, flotilin 1 and $\beta$-tubulin in whole cell extract and plasma membrane fraction were detected by western blotting as described in MATERIALS AND METHODS section. (B) Total RNA was extracted from cells used in (A) and GST $\pi$, caveolin-1 and GAPDH mRNAs were detected by semi-quantitative RT-PCR as described in MATERIALS AND METHODS section. 
culture medium of caveolin-1 knockdown cells contained GST $\pi$ and increased Vmax for spermidine uptake without changing $K m$ values (Table 1). These results indicated that GST $\pi$ increased the rate of polyamine internalization but did not affect the affinity for polyamine recognition by cells. Proteomic analysis and an immunofluorescence microscope revealed that $S$-glutathionylation of actin on the cell surface area was increased in caveolin-1 knockdown cells. Reversible $S$-glutathionylation of actin was reported to regulate actin polymerization and actin filament formation by inducing structural change [20, 21]. It was suggested that $S$-glutathionylation of actin filaments induced actin depolymerization. Shen and Turner reported that actin depolymerization induced caveolae-mediated endocytosis [22]. Our data shown in Figure 7 indicated the inhibition of actin depolymerization by jasplakinolide reduced spermidine uptake activity. Our results demonstrate that caveolin-1 negatively regulates caveolar

\section{A HCT116/Mock cultured in CS}
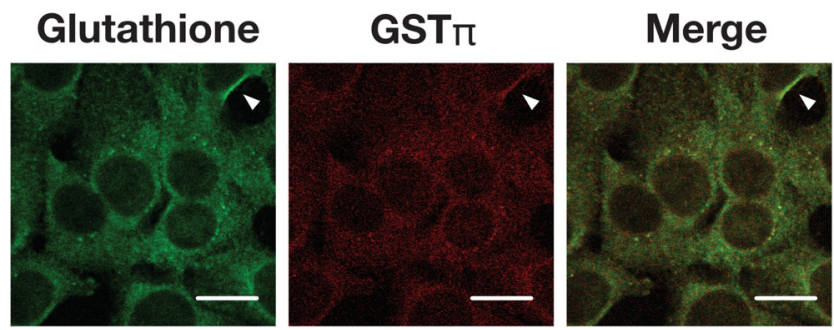

\section{HCT116/Cav-1 AS cultured in CS}
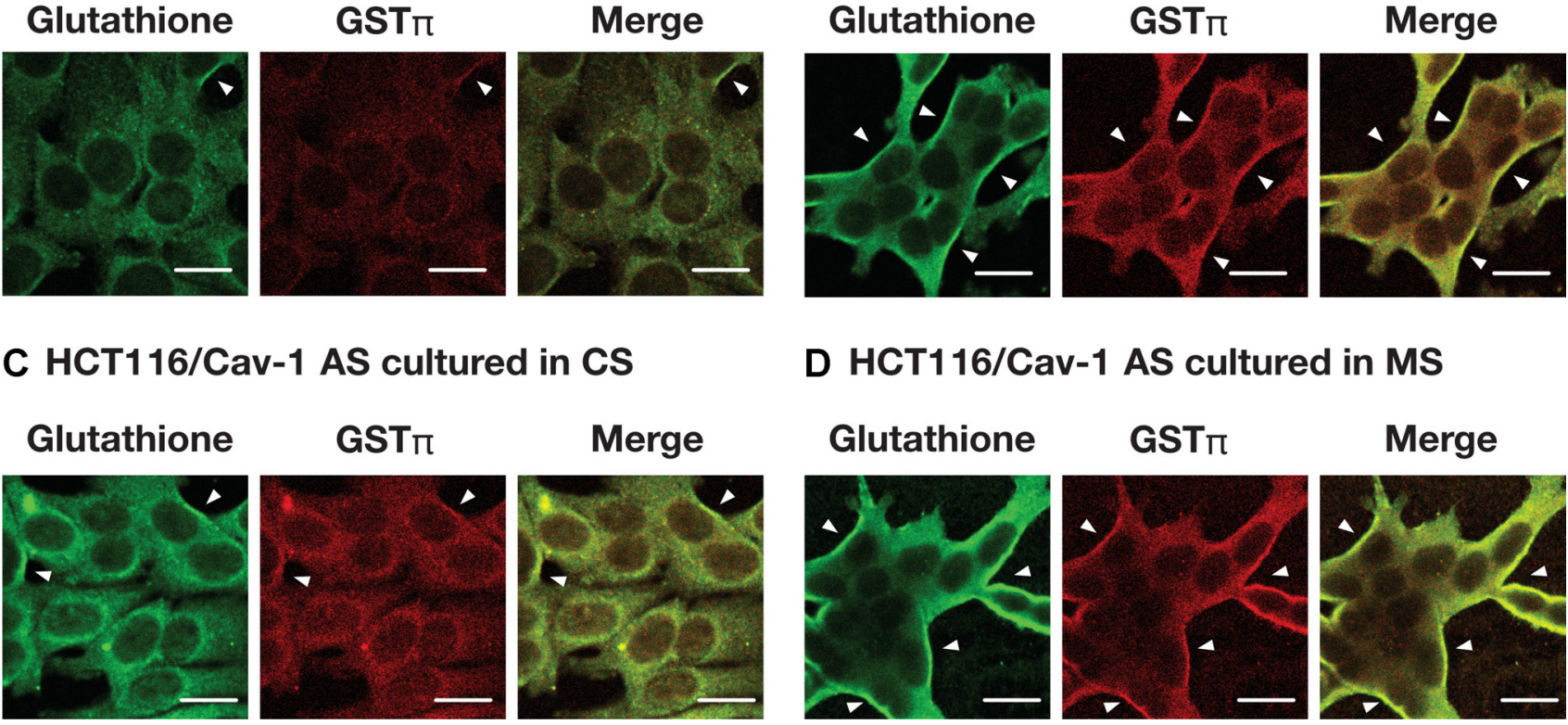

\section{HCT116/Cav-1 AS cultured in MS}

Figure 4: The effect of culture medium on $\boldsymbol{S}$-glutathionylated protein and GST $\pi$ levels. HCT116/Mock (A, B) and HCT116/ Cav-1 AS cells (C, D) were cultured in the control supernatant CS (A, C) or mutant supernatant MS (B, D). After 24 hours, cells were fixed and stained as described in MATERIALS AND METHODS section. $S$-glutathionylated proteins (green), GST $\pi$ (red) and merged images are shown. White arrowheads indicate the colocalization of $S$-glutathionylated proteins and GST $\pi$ on the plasma membrane. Bar $=20 \mu \mathrm{m}$.

A Silver stain

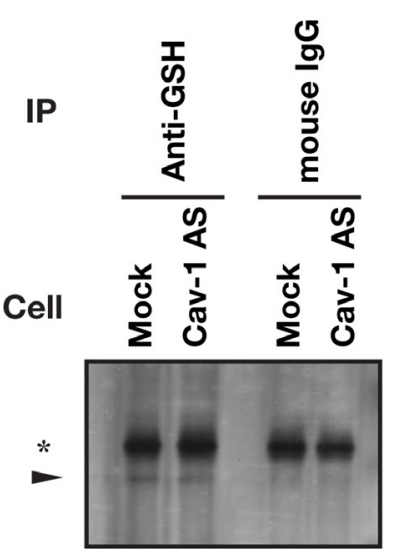

B WB: Anti-glutathione

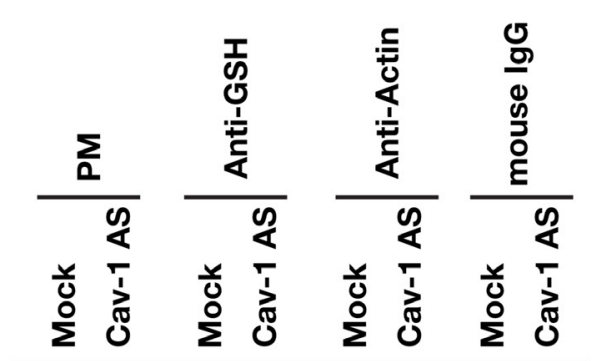

C WB: Anti-actin

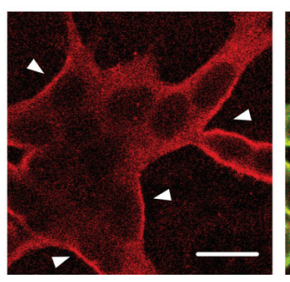

Merge

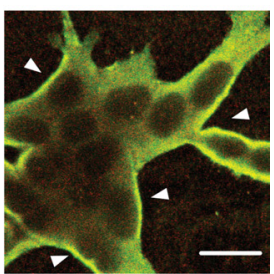

Figure 5: Identification of actin as a $\boldsymbol{S}$-glutathionylated protein. Plasma membrane fractions prepared from HCT116/Mock and HCT116/Cav-1 AS cells were subjected to immunoprecipitation with indicated antibodies as described in MATERIALS AND METHODS section. Antibody-protein complex were analyzed by silver stain (A) and western blot analysis for glutathione (B) and $\beta$-actin $(\mathbf{C})$ using TidyBlot: HRP conjugated western blot detection reagent. Arrowhead indicates $42 \mathrm{KDa}$ protein. *, a band from IgG. PM, plasma membrane. 
endocytosis dependent polyamine uptake by inhibiting GST $\pi$ secretion, which stimulates actin depolymerization and endocytosis.

As for polyamine transport, Belting et al. reported that nitric oxide mediated a release of polyamines

A HCT116/Mock
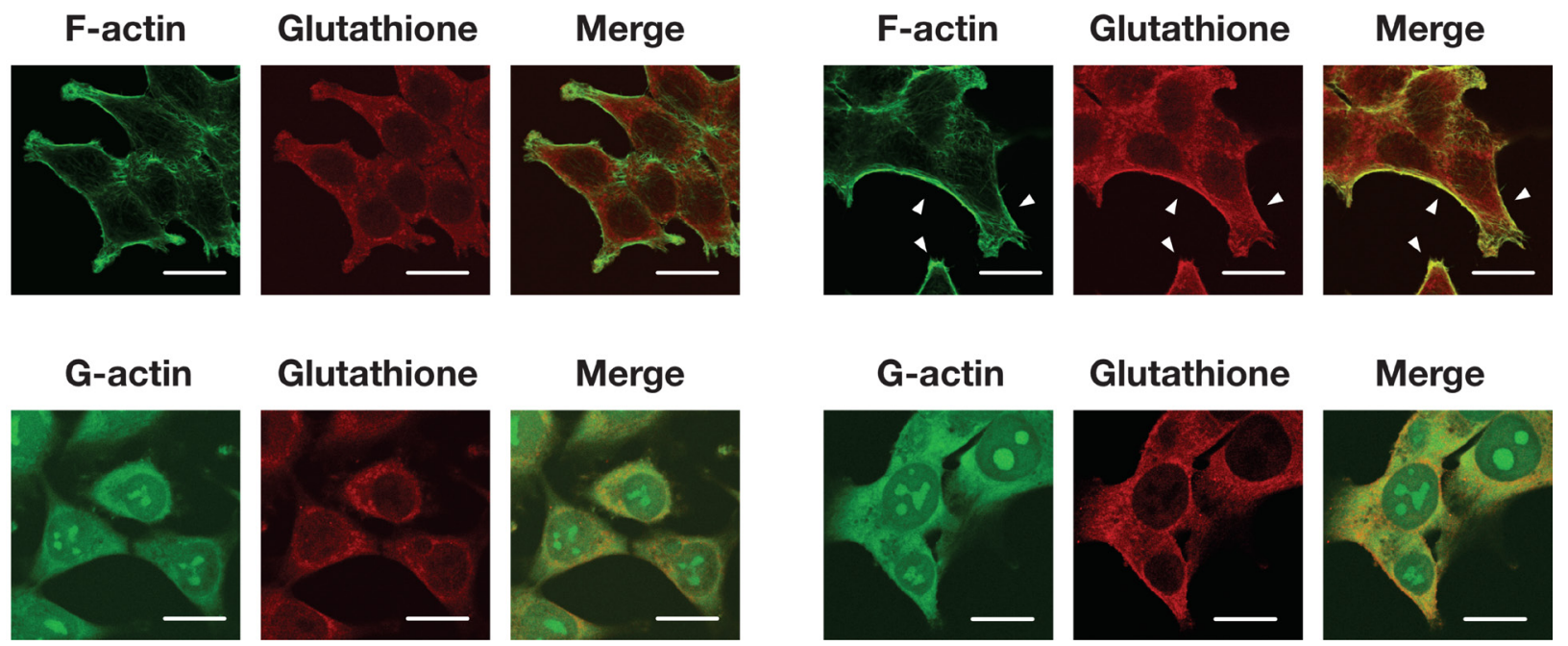
polyamine uptake in gastrointestinal tissues [11]. These reports suggest that the nitrosative stress is involved in the polyamines transport. In addition, the loss of caveolin-1

\section{B HCT116/Cav-1 AS}
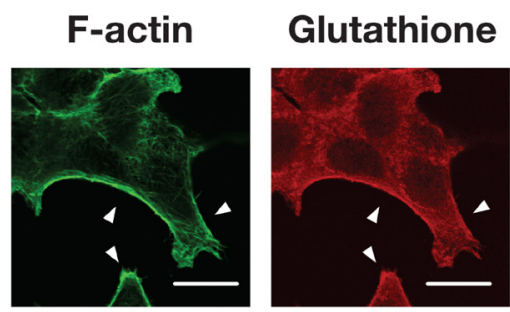

Figure 6: Cellular distribution of actin and $\boldsymbol{S}$-glutathionylated protein. HCT116/Mock (A) and HCT116/Cav-1 AS (B) cells were cultured for 2 days, fixed and stained for F-actin, G-actin and glutathione as described in MATERIALS AND METHODS section. F- and G-actin (green), glutathione (red) and merged images were shown. White arrowheads indicate colocalization of fluorescence from F-actin and $S$-glutathionylated proteins. Bar $=20 \mu \mathrm{m}$.

\section{A Spermidine uptake}

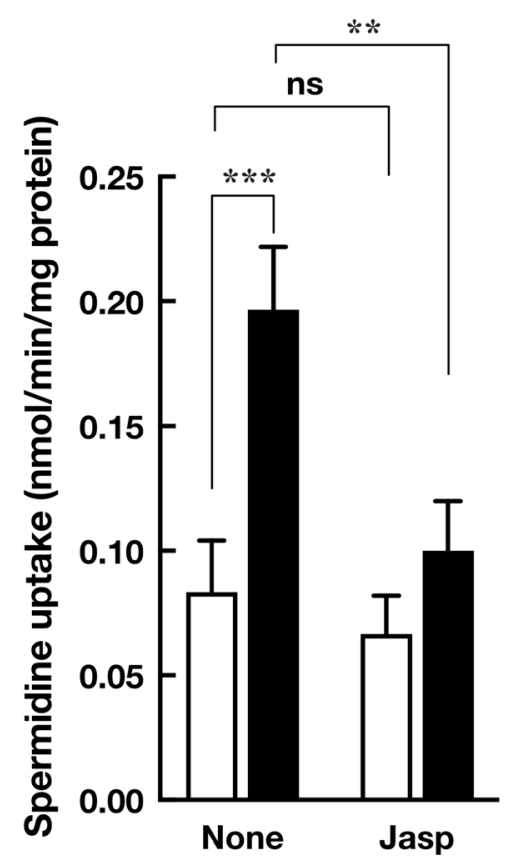

\section{B Cell viability}

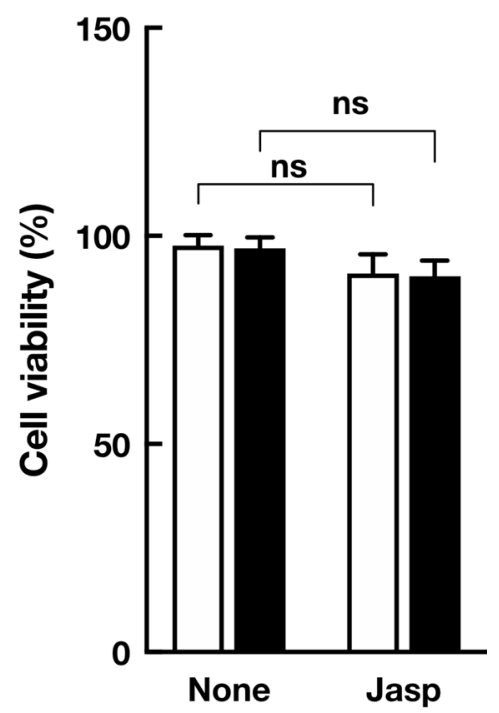

Figure 7: Effect of jasplakinolide on polyamine transport. (A) HCT116/Mock (white bar) and HCT116/Cav-1 AS cells (black bar) were cultured in the presence and absence of $100 \mathrm{nM}$ jasplakinolide for 4 hours and washed with transport assay buffer. Spermidine uptake activities were measured as described in MATERIALS AND METHODS section. (B) The viability of cells cultured in the presence and absence of $100 \mathrm{nM}$ jasplakinolide for 4 hours are counted. Values are mean $\pm \mathrm{SD}$ of triplicate determinations. ${ }^{*}, p<0.05,{ }^{* *}, p<0.01$, ns, not significant. 
induces nitrosative stress [24]. As Townsend et al. showed, actin was $S$-glutathionylated by GST $\pi$ under nitrosative stress condition [16]. Together with our results, it was suggested that nitrosative stress and $S$-glutathionylation could play important roles in polyamine uptake.

The role of caveolin-1 in GST $\pi$ secretion is not yet elucidated. Recently Han and Zhu reported that caveolin-1 negatively regulated cell invasion through regulating expression and secretion of matrix metalloproteinase [25]. Yamaguchi et al. reported that the secretion of insulinlike growth factor binding protein-5 (IGFBP-5) was decreased by caveolin-1 [26]. These reports suggested that caveolin-1 could affect the expression and secretion of several proteins. It is possible that the secretion of GST $\pi$ is regulated by the common mechanism underlying the secretion of these proteins. Our result indicated that caveolin-1 did not affect the expression level but altered the cellular distribution of GST $\pi$ (Figure 3 ). The effect of $1 \alpha, 25(\mathrm{OH})_{2}$ vitamin $\mathrm{D}_{3}$, an activated form of vitamin $\mathrm{D}_{3}$ on GST $\pi$ secretion and calreticulin knockingdown experiment suggested that the secretion of GST $\pi$ was not matrix vesicle dependent (data not shown). The inhibition of GST $\pi$ secretion by $1 \alpha, 25(\mathrm{OH})_{2}$ vitamin $\mathrm{D}_{3}$ was calreticulin independent (data not shown) and this suggested that cytosolic vitamin $\mathrm{D}$ receptor might regulate GST $\pi$ secretion in a caveolin-1-regulated manner. Since knocking down caveolin-1 increases endocytosis rate, it is possible that increased GST $\pi$ secretion in caveolin-1 knockdown cells involves altered endosomal sorting processes and vesicular recycling pathway due to the increased endocytosis and potential change of cellular localization of GST $\pi$. Further study is needed to clarify the molecular mechanisms of caveolin-regulated GST $\pi$ secretion.

Our results suggest that high expression of GST $\pi$ can cause an increase in polyamine uptake. A high expression of GST $\pi$ is reported in human colorectal polyps and its expression level was correlated with the grade of adenoma [27]. In addition, it was reported that $N$-Myc upregulates GST $\pi$ expression in neuroblastoma [28]. Since uptake of dietary and luminal bacterial polyamines significantly contributes to tissue polyamine levels and overcomes the effect of the polyamine biosynthesis inhibitor DFMO in mice model [29], a combination of polyamine biosynthesis inhibitor and uptake blocker is a potential strategy for cancer treatment and prevention. Indeed, it is reported that a combination of polyamine biosynthesis inhibitor and uptake blocker reduced tumor progression and prolongs survival in mouse models of neuroblastoma [30] as well as pancreatic cancer model mice [31]. Our study provides a novel target and strategy for cancer prevention and treatment using polyamine transport inhibitors in GST $\pi$ expressing cells. For example, a GST $\pi$ inhibitor such as 4-aryl-1,3,4-oxazolylium-5-olate [32] can be used for cancer prevention and treatment with a combination of DFMO. However, GSTs are involved in the detoxification of xenobiotics as well as oxidative stress [33]. Inhibition of GSTs may increase the risk of other disease such as brain stroke [34]. To maximize the therapeutic effect, the toxicity of the treatment should be carefully monitored. The effect of GST $\pi$ inhibitor on polyamine transport and its therapeutic efficacy will be examined in the future.

\section{MATERIALS AND METHODS}

\section{Cell culture}

The human colorectal carcinoma cell lines HCT116, transfected with mock vector (HCT116/Mock) or caveolin-1 antisense (HCT116/Cav-1 AS), were a kind gift from Dr. B. Sloane and Dr. D. Cavallo-Medved [35]. The caveolin-1 was downregulated more than $80 \%$ in HCT116/ Cav-1 AS cells compared to the TCH116/Mock cells. The growth and cell viability in both cell lines were the same under this culture condition. Cells were maintained in Dulbecco's Modified Essential Medium (DMEM) supplemented with $10 \%$ fetal bovine serum (FBS), $1 \%$ penicillin/streptomycin $(\mathrm{P} / \mathrm{S})$ and $0.5 \mathrm{mg} / \mathrm{mL}$ puromycin. Cells were maintained in a humidified incubator at $37^{\circ} \mathrm{C}$ with $5 \% \mathrm{CO}_{2}$. The viability of cells was monitored by staining with $0.2 \%$ trypan blue solution.

\section{Spermidine transport assay}

Assays were performed as described previously [10] using $\left[{ }^{3} \mathrm{H}\right]$ spermidine (37 MBq/mmol, GE Healthcare) as a substrate. One million cells were cultured on a 6-well plate (greiner bio) for 2 day and the culture medium were collected, centrifuged and filtered through a $0.22 \mu \mathrm{m}$ filter (Millipore). Another one million cells were cultured on a 6-well plate for 1 day and the culture medium were changed to the collected medium. Cells were cultured for another 2 days before spermidine transport assay. After 2 days, cells were washed with transport assay buffer containing $5 \mathrm{mM}$ Hepes- $\mathrm{NaOH}, \mathrm{pH}$ 7.4, $145 \mathrm{mM} \mathrm{NaCl}$, $3 \mathrm{mM} \mathrm{KCl}, 1 \mathrm{mM} \mathrm{CaCl}_{2}, 0.5 \mathrm{mM} \mathrm{MgCl}_{2}$ and $5 \mathrm{mM}$ glucose and incubated in the same buffer for $5 \mathrm{~min}$ at $37^{\circ} \mathrm{C}$. Spermidine uptake was started by the addition of $\left[{ }^{3} \mathrm{H}\right]$ spermidine. After $5 \mathrm{~min}$ incubation, cells were washed twice with ice-cold assay buffer containing $1 \mathrm{mM}$ spermidine. Cells were lysed in $0.5 \mathrm{~N} \mathrm{NaOH}$ and radioactivity was counted using a Beckman LS 5000TD scintillation counter. Total cellular protein was determined by the bicinchonic acid protein assay kit (Pierce). When the effect of the antibody was tested, anti-GST $\pi$ antibody (abcam) and normal goat IgG were washed by diluting 1000-fold with serum-free DMEM and filtering through a microcon concentrator 3 centrifugal filters (amicon) three times to remove sodium azide. Cells were cultured with $0.5 \mathrm{mg} / \mathrm{mL}$ antibodies or $10 \mathrm{ng} / \mathrm{mL}$ of purified human GST $\pi$ protein (Alpha Diagnostics International) for 24 hours and polyamine uptake was measured. 
For jasplakinolide treatment, cells were cultured with $100 \mathrm{nM}$ jasplakinolide (Invitrogen) for 4 hours prior to the spermidine transport assay.

\section{Liquid chromatography coupled to tandem mass spectrometry (MS/MS) analysis}

HCT116/Mock and HCT116/Cav-1 AS cells were cultured in the serum-free Opti-MEM I (GIBCO). After 2 days, media were collected, filtered through cellulose nitrate filter (pore size $0.2 \mathrm{~mm}$, NALGENE) and incubated on ice with 5\% trichloroacetic acid for $30 \mathrm{~min}$. Proteins in media were precipitated by centrifugation at $16,000 \times \mathrm{g}$ for $30 \mathrm{~min}$ and then resolved on $12 \%$ SDS polyacrylamide gel and stained using ProteoSilver Plus Silver Stain Kit (Sigma). Bands highly expressed in HCT116/Cav-1 AS cell culture medium were excised and digested with trypsin for 16 hours (20). The extracted peptides from the gel following digestion were analyzed by a ThermoFinnigan LTQ ion trap mass spectrometer (San Jose, CA) equipped with a Michrom Paradigm MS4 HPLC (Auburn, CA) and a nanoelectrospray source as described previously (11). All spectra were searched against the ipi. HUMAN. v.3.27 protein database which, at the time of download, contained 67,528 protein entries (ftp://ftp.ebi.ac.uk/pub/databases/ IPI/current/). MS/MS spectra were searched with Sequest and $\mathrm{X}$ !Tandem and results compiled using Scaffold as previously described [10].

\section{Preparation of plasma membrane fraction}

A plasma membrane fraction was prepared by the method of Nishiumi and Ashida [36]. Cells were suspended in buffer A $(50 \mathrm{mM}$ Tris, $\mathrm{pH} 8.0,0.1 \%$ Nonident P-40 (NP-40), $10 \mathrm{mg} / \mathrm{mL}$ aprotinin, $500 \mu \mathrm{M}$ sodium orthovanidate, and $10 \mathrm{mg} / \mathrm{mL}$ phenylmethylsulfonyl fluoride) and passed three times through a 25-guage needle. The homogenate was centrifuged at $1,000 \mathrm{~g}$ for $10 \mathrm{~min}$ at $4^{\circ} \mathrm{C}$, and the precipitate was suspended in NP40 free buffer A, kept on ice for 10 min and centrifuged at $1,000 \mathrm{~g}$ for $10 \mathrm{~min}$ at $4^{\circ} \mathrm{C}$. The precipitate was suspended in buffer A containing 1\% NP-40, kept on ice for 1 hour and centrifuged at $16,000 \mathrm{~g}$ for $20 \mathrm{~min}$ at $4^{\circ} \mathrm{C}$. The supernatant was collected as a plasma membrane fraction.

\section{Western blotting}

Cells were washed with buffered saline and lysed in $10 \mathrm{mM}$ Tris- $\mathrm{HCl}, \mathrm{pH} 8.0$ containing $10 \mathrm{mg} / \mathrm{mL}$ aprotinin, $500 \mu \mathrm{M}$ sodium orthovanidate and $10 \mathrm{mg} / \mathrm{mL}$ phenylmethylsulfonyl fluoride, and used as whole cell lysate. Forty $\mathrm{mg}$ protein was separated on a $10 \%$ polyacrylamide gel. Proteins were transferred electrophoretically to a Hybound-C nitrocellulose membrane (Amersham, Arlington Heights, IL). Blots were blocked in $5 \%$ nonfat dry milk in tris buffered saline containing $0.1 \%$ Tween 20 (TBS-T) for $30 \mathrm{~min}$ at room temperature. GST $\pi, S$-glutathionylated proteins, caveolin-1, $\beta$-actin, $\beta$-tubulin, flotilin and calreticulin were detected by ECL Western Blotting Detection System (GE Healthcare) using anti-GST $\pi$ (1:3000 dilution, Abcam), anti-glutathione (1:10000 dilution, Abcam), anti-caveolin-1 (1:10000 dilution, SANTA CRUZ BIOTECHNOLOGY), anti- $\beta$-actin (1:10000 dilution, Abcam), anti- $\beta$-tubulin (1:10000 dilution, SANTA CRUZ BIOTECHNOLOGY), anti-flotilin (1:1000 dilution, Cell Signaling) and anticalreticulin (1:1000, abcam) as primary antibodies.

\section{Semiquantitative RT-PCR analysis}

Total RNA was isolated using the Qiagen RNeasy Kit according to the manufacturer's protocol. Two micrograms of total RNA were treated with RNasefree deoxyribonuclease I (Fermentas Life Science) and reverse transcribed into cDNA using the M-MuLV reverse transcriptase (Fermentas Life Science). The DNA fragments of GST $\pi$, caveolin-1 and glyceraldehyde 3-phosphate dehydrogenase (GAPDH) were amplified using primer sets of GSTP1-F (5'-TATTTCCCAGTTCGAGGCCG-3') and GSTP1-R (5'-ATTGATGGGGAGGTTCACGTA-3') for GST $\pi$, SLC3A2-F, CAV1-F (5'-TCAACCGCGACCCTAA ACACC-3') and CAV1-R (5'-TGAAATAGCTCAGAAG AGACAT-3') for caveolin-1, GAPDH-F (5'-TGGTATCG TGGAAGGACTCGTGGAAGGACTCATGAC- ${ }^{\prime}$ ) and GAPDH-R (5'-AGAGTCCAGTGAGCTTCCCGTTCA GC-3') for GAPDH.

\section{Indirect immunofluorescence microscopy}

HCT116/Mock and HCT116/Cav-1 AS cells were cultured on cover slips, washed with buffered saline and fixed in $2 \%$ paraformaldehyde for 15 minutes at $37^{\circ} \mathrm{C}$. Cells were then permeabilized with acetone for 30 seconds at $-20^{\circ} \mathrm{C}$, treated with $1 \%$ bovine serum albumin in PBS for $1 \mathrm{~h}$ at room temperature and incubated with primary antibody for 16 hours at $4^{\circ} \mathrm{C}$. Cells were washed 5 times with the same buffer and incubated with fluorophore labeled secondary antibody for 16 hours at $4^{\circ} \mathrm{C}$. Cellular F- or G-actin was stained using Alexa Fluor 488 conjugated phalloidin or DNase I (Invitrogen), respectively. After incubation, cells were washed 5 times and mounted in Prolong Gold Mounting Solution (Clontech). Fluorescence was visualized using a Nikon PCM2000 Confocal Microscope (Nikon) or Leica SP5 High-speed Spectral Confocal Microscope (Leica).

\section{Immunoprecipitation}

Immunoprecipitation was performed as previously described [10] with modifications. One hundred mg of plasma membrane protein was incubated with antiglutathione or anti- $\beta$-actin (Abcam) antibodies in IP buffer (50 mM Tris- $\mathrm{HCl}, \mathrm{pH} 8.0,120 \mathrm{mM} \mathrm{NaCl}, 0.5 \%$ $\mathrm{NP}-40$ ) at $4^{\circ} \mathrm{C}$ for $16 \mathrm{~h}$. Plasma membrane mixture were 
incubated with protein A agarose beads (SANTA CRUZ BIOTECHNOLOGY) for $16 \mathrm{~h}$ at $4^{\circ} \mathrm{C}$ and washed 5 times with IP buffer. Beads were suspended with $40 \mathrm{ml}$ of SDS-sample buffer and boiled for $5 \mathrm{~min}$. Proteins were separated on a $10 \%$ SDS-acrylamide gel, transferred to a Hybound-C nitrocellulose membrane and detected as described above using TidyBlot Western blot detection reagent: HRP (BioRad) to reduce the background from IgG. The protein that immunoprecipitated with antiglutathione antibody was identified as descried above.

\section{Statistical analysis}

Statistical analysis was performed using GraphPad Prism version 6.0d for Mac, GraphPad Software, La Jolla California USA, www.graphpad.com. Differences between two groups were compared using Student's t-test. For comparison of multiple groups, one-way ANOVA followed by Tukey's multiple comparisons test was used. A $p$-value $<0.05$ was considered statistically significant.

The datasets generated during and/or analyzed during the current study are available from the corresponding author on reasonable request.

\section{Author contributions}

T. U. conceived, designed and performed the experiments. G. T. performed the proteomic analysis. T. U. and E. W. G. interpreted the experiments. T. U. and E. W. G. wrote the manuscripts. All authors reviewed the manuscript.

\section{ACKNOWLEDGMENTS}

We thank Dr. B. Sloane and Dr. D. Cavello-Medved, Department of Pharmacology, Barbara Karmanos Cancer Institute, Wayne State University, School of Medicine, Detroit, MI for providing HCT116/Mock and HCT116/ Cav-1 AS cells.

\section{CONFLICTS OF INTEREST} interests.

The authors declare that they have no competing

\section{FUNDING}

Mass spectrometric data was acquired by the support of NIEHS grant ES06694 to the SWEHSC, NIH/NCI grant CA023074 to the AZCC and by the BIO5 Institute of the University of Arizona.

\section{REFERENCES}

1. Igarashi K, Kashiwagi K. Modulation of cellular function by polyamines. Int J Biochem Cell Biol. 2010; 42:39-51. https://doi.org/10.1016/j.biocel.2009.07.009. [PubMed]
2. Igarashi $\mathrm{K}$, Kashiwagi $\mathrm{K}$. The functional role of polyamines in eukaryotic cells. Int J Biochem Cell Biol. 2019; 107:104115. https://doi.org/10.1016/j.biocel.2018.12.012. [PubMed]

3. Uemura T, Higashi K, Takigawa M, Toida T, Kashiwagi $\mathrm{K}$, Igarashi K. Polyamine modulon in yeast-Stimulation of COX4 synthesis by spermidine at the level of translation. Int J Biochem Cell Biol. 2009; 41:2538-2545. https://doi. org/10.1016/j.biocel.2009.08.010. [PubMed]

4. Igarashi K, Kashiwagi K. Polyamine Modulon in Escherichia coli: genes involved in the stimulation of cell growth by polyamines. J Biochem. 2006; 139:11-16. https://doi.org/10.1093/jb/mvj020. [PubMed]

5. Igarashi K, Kashiwagi K. Effects of polyamines on protein synthesis and growth of Escherichia coli. J Biol Chem. 2018; 293:18702-18709. https://doi.org/10.1074/jbc. TM118.003465. [PubMed]

6. Park MH, Wolff EC. Hypusine, a polyamine-derived amino acid critical for eukaryotic translation. J Biol Chem. 2018; 293:18710-18718. $\quad$ https://doi.org/10.1074/jbc. TM118.003341. [PubMed]

7. Tome ME, Fiser SM, Payne CM, Gerner EW. Excess putrescine accumulation inhibits the formation of modified eukaryotic initiation factor 5A (eIF-5A) and induces apoptosis. Biochem J. 1997; 328:847-854. https://doi. org/10.1042/bj3280847. [PubMed]

8. Abdulhussein AA, Wallace HM. Polyamines and membrane transporters. Amino Acids. 2014; 46:655-660. https://doi. org/10.1007/s00726-013-1553-6. [PubMed]

9. Larqué E, Sabater-Molina M, Zamora S. Biological significance of dietary polyamines. Nutrition. 2007; 23:8795. https://doi.org/10.1016/j.nut.2006.09.006. [PubMed]

10. Uemura T, Yerushalmi HF, Tsaprailis G, Stringer DE, Pastorian KE, Hawel L 3rd, Byus CV, Gerner EW. Identification and characterization of a diamine exporter in colon epithelial cells. J Biol Chem. 2008; 283:2642826435. https://doi.org/10.1074/jbc.M804714200. [PubMed]

11. Uemura T, Stringer DE, Blohm-Mangone KA, Gerner EW. Polyamine transport is mediated by both endocytic and solute carrier transport mechanisms in the gastrointestinal tract. Am J Physiol Gastrointest Liver Physiol. 2010; 299:G517-G522. https://doi.org/10.1152/ajpgi.00169.2010. [PubMed]

12. Roy UKB, Rial NS, Kachel KL, Gerner EW. Activated K-RAS increases polyamine uptake in human colon cancer cells through modulation of caveolar endocytosis. Mol Carcinog. 2008; 47:538-553. https://doi.org/10.1002/ mc.20414. [PubMed]

13. Lamaze C, Tardif N, Dewulf M, Vassilopoulos S, Blouin $\mathrm{CM}$. The caveolae dress code: structure and signaling. Curr Opin Cell Biol. 2017; 47:117-125. https://doi.org/10.1016/j. ceb.2017.02.014. [PubMed]

14. Henkhaus RS, Roy UKB, Cavallo-Medved D, Sloane BF, Gerner EW, Ignatenko NA. Caveolin-1-mediated expression and secretion of kallikrein 6 in colon cancer 
cells. Neoplasia. 2008; 10:140-148. https://doi.org/10.1593/ neo.07817. [PubMed]

15. Parton RG, Simons K. The multiple faces of caveolae. Nat Rev Mol Cell Biol. 2007; 8:185-194. https://doi. org $/ 10.1038 / \mathrm{nrm} 2122$. [PubMed]

16. Townsend DM, Manevich Y, He L, Hutchens S, Pazoles CJ, Tew KD. Novel role for glutathione S-transferase pi. Regulator of protein S-Glutathionylation following oxidative and nitrosative stress. J Biol Chem. 2009; 284:436-445. https://oi.org/10.1074/jbc.M805586200. [PubMed]

17. Dalle-Donne I, Carini M, Vistoli G, Gamberoni L, Giustarini D, Colombo R, Maffei Facino R, Rossi R, Milzani A, Aldini G. Actin Cys374 as a nucleophilic target of alpha,betaunsaturated aldehydes. Free Radic Biol Med. 2007; 42:583598. https://doi.org/10.1016/j.freeradbiomed.2006.11.026. [PubMed]

18. Mundy DI, Machleidt T, Ying YS, Anderson RGW, Bloom GS. Dual control of caveolar membrane traffic by microtubules and the actin cytoskeleton. J Cell Sci. 2002; 115:4327-4339. https://doi.org/10.1242/jcs.00117. [PubMed]

19. Holzinger A. Jasplakinolide. An actin-specific reagent that promotes actin polymerization. Methods Mol Biol. 2001; 161:109-120. https://doi.org/10.1385/1-59259-051-9:109. [PubMed]

20. Dalle-Donne I, Giustarini D, Rossi R, Colombo R, Milzani A. Reversible S-glutathionylation of Cys 374 regulates actin filament formation by inducing structural changes in the actin molecule. Free Radic Biol Med. 2003; 34:23-32. https://doi.org/10.1016/S0891-5849(02)01182-6. [PubMed]

21. Wang J, Boja ES, Tan W, Tekle E, Fales HM, English S, Mieyal JJ, Chock PB. Reversible glutathionylation regulates actin polymerization in A431 cells. J Biol Chem. 2001; 276:47763-47766. https://doi.org/10.1074/jbc.C100415200. [PubMed]

22. Shen L, Turner JR. Actin depolymerization disrupts tight junctions via caveolae-mediated endocytosis. Mol Biol Cell. 2005; 16:3919-3936. https://doi.org/10.1091/mbc.e04-121089. [PubMed]

23. Belting M, Mani K, Jönsson M, Cheng F, Sandgren S, Jonsson S, Ding K, Delcros JG, Fransson LA. Glypican-1 is a vehicle for polyamine uptake in mammalian cells: a pivital role for nitrosothiol-derived nitric oxide. J Biol Chem. 2003; 278:47181-47189. https://doi.org/10.1074/ jbc.M308325200. [PubMed]

24. Wunderlich C, Schober K, Lange SA, Drab M, BraunDullaeus RC, Kasper M, Schwencke C, Schmeisser A, Strasser RH. Disruption of caveolin-1 leads to enhanced nitrosative stress and severe systolic and diastolic heart failure. Biochem Biophys Res Commun. 2006; 340:702708. https://doi.org/10.1016/j.bbrc.2005.12.058. [PubMed]

25. Han F, Zhu HG. Caveolin-1 regulating the invasion and expression of matrix metalloproteinase (MMPs) in pancreatic carcinoma cells. J Surg Res. 2010; 159:443-450. https://doi.org/10.1016/j.jss.2009.03.079. [PubMed]

26. Yamaguchi Y, Yasuoka H, Stolz DB, Feghali-Bostwick CA. Decreased caveolin-1 levels contribute to fibrosis and deposition of extracellular IGFBP-5. J Cell Mol Med. 2011; 15:957-969. https://doi.org/10.1111/j.15824934.2010.01063.x. [PubMed]

27. Gaitanarou E, Seretis E, Xinopoulos D, Paraskevas E, Arnoyiannaki N, Voloudakis-Baltatzis I. Immunohistochemical localization of glutathione S-transferase-pi in human colorectal polyps. World J Gastroenterol. 2008; 14:4179-4184. https://doi.org/10.3748/ wjg. 14.4179. [PubMed]

28. Fletcher JI, Gherardi S, Murray J, Burkhart CA, Russell A, Valli E, Smith J, Oberthuer A, Ashton LJ, London WB, Marshall GM, Norris MD, Perini G, Haber M. $\mathrm{N}-\mathrm{Myc}$ regulates expression of the detoxifying enzyme glutathione transferase GSTP1, a marker of poor outcome in neuroblastoma. Cancer Res. 2012; 72:845-853. https:// doi.org/10.1158/0008-5472.CAN-11-1885. [PubMed]

29. Hessels J, Kingma AW, Ferwerda H, Keij J, van den Berg GA, Muskiet FA. Microbial flora in the gastrointestinal tract abolishes cytostatic effects of alpha-difluoromethylornithine in vivo. Int J Cancer. 1989; 43:1155-1164. https://doi. org/10.1002/ijc.2910430632. [PubMed]

30. Gamble LD, Purgato S, Murray J, Xiao L, Yu DM, Hanssen KM, Giorgi FM, Carter DR, Gifford AJ, Valli E, Milazzo G, Kamili A, Mayoh C, et al. Inhibition of polyamine synthesis and uptake reduces tumor progression and prolongs survival in mouse models of neuroblastoma. Sci Transl Med. 2019; 11:eaau1099. https://doi.org/10.1126/scitranslmed.aau1099. [PubMed]

31. Gitto SB, Pandey V, Oyer JL, Copik AJ, Hogan FC, Phanstiel O 4th, Altomare DA. Difluoromethylornithine Combined with a Polyamine Transport Inhibitor Is Effective against Gemcitabine Resistant Pancreatic Cancer. Mol Pharm. 2018; 15:369-376. https://doi.org/10.1021/acs. molpharmaceut.7b00718. [PubMed]

32. Cui H, Shen J, Lu D, Zhang T, Zhang W, Sun D, Wang PG. 4-Aryl-1,3,2-oxathiazolylium-5-olate: a novel GST inhibitor to release JNK and activate c-Jun for cancer therapy. Cancer Chemother Pharmacol. 2008; 62:509-515. https://doi.org/10.1007/s00280-007-0632-3. [PubMed]

33. Allocati N, Masulli M, Di Ilio C, Federici L. Glutathione transferases: substrates, inihibitors and pro-drugs in cancer and neurodegenerative diseases. Oncogenesis. 2018; 7:8. https://doi.org/10.1038/s41389-017-0025-3. [PubMed]

34. Uemura T, Watanabe K, Ko K, Higashi K, Kogure N, Kitajima M, Takayama H, Takao K, Sugita Y, Sakamoto A, Terui Y, Toida T, Kashiwagi K, Igarashi K. Protective Effects of Brain Infarction by N-Acetylcysteine Derivatives. Stroke. 2018; 49:1727-1733. https://doi.org/10.1161/ STROKEAHA.118.021755. [PubMed]

35. Cavallo-Medved D, Mai J, Dosescu J, Sameni M, Sloane BF. Caveolin-1 mediates the expression and localization of 
cathepsin B, pro-urokinase plasminogen activator and their cell-surface receptors in human colorectal carcinoma cells.

J Cell Sci. 2005; 118:1493-1503. https://doi.org/10.1242/ jcs.02278. [PubMed]

36. Nishiumi S, Ashida H. Rapid preparation of a plasma membrane fraction from adipocytes and muscle cells: application to detection of translocated glucose transporter 4 on the plasma membrane. Biosci Biotechnol Biochem. 2007; 71:2343-2346. https://doi.org/10.1271/bbb.70342. [PubMed] 